\title{
Inheritance studies of apple scab resistance and identification of Rvi14, a new major gene that acts together with other broad-spectrum QTL
}

\author{
V. Soufflet-Freslon, L. Gianfranceschi, A. Patocchi, and C.-E. Durel
}

\begin{abstract}
Scab, caused by the fungal pathogen Venturia inaequalis, is the most common disease of cultivated apple (Malus $\times$ domestica). The fungal races 6 and 7 have now overcome the major resistance gene $V f$, which is widely used in apple breeding programmes. New breeding strategies to achieve durable resistance are thus necessary. The aim of this study was to determine the genetic basis of quantitative resistance of the apple cultivar 'Dülmener Rosenapfel', known to be scab resistant under different environmental conditions. An $\mathrm{F}_{1}$ progeny derived from the cross between the susceptible cultivar 'Gala' and 'Dülmener Rosenapfel' was tested in a greenhouse with a multi-isolate inoculum of V. inaequalis. Rvi14, a new major gene that conditions a chlorotic-type reaction, was mapped on linkage group (LG) 6 in a genomic region not known to be involved in disease resistance. A further three quantitative trait loci (QTL) for resistance were identified. One co-localized with Rvi14 on LG6, whereas the remaining two were detected on LG11 and LG17, in genomic regions already reported to carry broad-spectrum QTL in other genetic backgrounds. Since a selective genotyping approach was used to detect QTL, an expectation-maximization (EM) computation was used to estimate the corrected QTL contributions to phenotypic variation and was validated by entire progeny genotyping.

Key words: Malus $\times$ domestica, Venturia inaequalis, major gene, quantitative resistance, genetic mapping.

Résumé : La tavelure, causée par le champignon pathogène Venturia inaequalis, est la maladie du pommier cultivé (Malus $\times$ domestica) la plus répandue. Les races 6 et 7 du champignon ont maintenant contourné le gène majeur de résistance $V f$, largement utilisé dans les programmes d'amélioration du pommier. De nouvelles stratégies d'amélioration sont alors nécessaires en vue d'une résistance durable. Le but de cette étude était d'étudier le déterminisme génétique de la résistance quantitative de la variété de pommier 'Dülmener Rosenapfel', connue pour être résistante à la tavelure dans différentes conditions environnementales. Une descendance $F_{1}$ issue du croisement entre la variété sensible 'Gala' et 'Dülmener Rosenapfel' a été testée en serre avec un inoculum multi-souches de $V$. inaequalis. Un nouveau gène majeur, Rvi14, déterminant une réaction de type chlorotique, a été localisé sur le groupe de liaison (GL) 6 dans une région génomique pas encore connue pour être impliquée dans la résistance aux maladies. Trois QTL (« quantitative trait loci ») de résistance ont été identifiés. Un a co-localisé avec Rvil4 sur le GL6 alors que les deux autres ont été détectés sur le GL11 et le GL17, dans des régions génomiques déjà connues pour porter des QTL à large spectre dans d'autres fonds génétiques. Les QTL ayant été détectés par génotypage sélectif, leur contribution à la variation phénotypique a été corrigée par maximum de vraisemblance; cette méthode corrective a ensuite été validée par le génotypage de la population entière.
\end{abstract}

Mots-clés : Malus $\times$ domestica, Venturia inaequalis, gène majeur, résistance quantitative, cartographie génétique.

\section{Introduction}

Apple scab, caused by the fungal pathogen Venturia inaequalis (Cooke) G. Wint., is one of the most prevalent diseases in apple-growing areas with high spring and summer rainfall. Most commercial apple cultivars (Malus $\times$ domestica) are susceptible to this disease and its control requires up to $12-15$ fungicide treatments per season. It is now crucial to reduce such intensive use of pesticides in apple orchards for environmental and consumer health reasons and because of the appearance of fungicide resistance. Growing genetically resistant or tolerant apple cultivars should provide an alternative to chemical control of the disease, provided that this resistance is durable.

Received 13 December 2007. Accepted 12 May 2008. Published on the NRC Research Press Web site at genome.nrc.ca on 18 July 2008. Corresponding Editor: M. Francki.

V. Soufflet-Freslon and C.-E. Durel. ${ }^{2}$ INRA, UMR 1259 GenHort, F-49071 Beaucouzé, France; IFR 149 Quasav, F-49045 Angers, France.

L. Gianfranceschi. UNIMI, Università degli Studi di Milano, Dipartimento di Scienze Biomolecolari e Biotecnologie, 20133 Milano, Italy.

A. Patocchi. ${ }^{1}$ Plant Pathology, Institute of Integrative Biology (IBZ), ETH Zurich, 8092 Zurich, Switzerland.

${ }^{1}$ Present address: Agroscope Changins-Wädenswil, Plant Protection, Phytopathology, CH-8820 Wädenswil, Switzerland.

${ }^{2}$ Corresponding author (e-mail: Charles-Eric.Durel@angers.inra.fr). 
Scab resistance studies have been focused on identifying major resistance genes, mainly in small-fruited Asiatic $M a$ lus species. These include $V f$ and $V f h$ from Malus floribunda 821 (Williams and Kuc 1969; Bénaouf and Parisi 2000); Vr$D W, V h 2$ (also called $V r$ or $V r-A$ ), and $V h 4$ (also called $V x$ or Vrl) from Malus pumila R12740-7A (Dayton and Williams 1968; Aldwinckle et al. 1976; Hemmat et al. 2002; Bus et al. 2005a; Boudichevskaia et al. 2006); Vh8 from Malus sieversii (Bus et al. 2005b); Vbj from Malus baccata jackii (Williams and Kuc 1969); Vb from 'Hansen's baccata \#2' (Williams and Kuc 1969); Va from PI172623 (Lespinasse 1989); Vm from Malus micromalus 245-38 or Malus atrosanguinea 804 (Williams and Kuc 1969); Vg from 'Golden Delicious' (Bénaouf and Parisi 1997); Vr2 from GMAL 2473 (Patocchi et al. 2004); and Vd from 'Durello di Forli' (Tartarini et al. 2004). Most of these resistance genes have been mapped in the apple genome (for a review, see Gessler et al. 2006), but only the $V f$ gene has been widely introgressed into the apple selections released over the last 50-60 years (Laurens 1999). However, in the late 1980s, Vf was overcome by two new $V$. inaequalis races (race 6 , Parisi et al. 1993; race 7, Bénaouf and Parisi 2000). The identification of different fungal races with the ability to overcome specific apple scab resistance genes triggered a need to develop new breeding strategies to promote durable resistance.

Pyramiding of several resistance genes within the same genetic background has been proposed to develop apple cultivars with durable scab resistance (MacHardy et al. 2001; Gessler et al. 2006). However, pyramiding of major resistance genes has proven to be risky in pathosystems such as lettuce-Bremia lactucae (Lebeda 1992). Conversely, polygenic quantitative resistance is considered to be more durable (Burdon 1993; Parlevliet 1993, 2002; Lindhout 2002), and combining major and minor resistance genes could offer more stable resistance than combining only major genes. A research programme is thus underway at INRA, Angers, France, to detect quantitative trait loci (QTL) for scab resistance. QTL were identified in the cultivars 'Fiesta', 'Discovery', and 'TN10-8' after inoculation of two segregating progenies with several monoconidial isolates in controlled conditions (Durel et al. 2003; Calenge et al. 2004). Some of these QTL were also identified in 'Fiesta' $\times$ 'Discovery' progeny grown in unsprayed fields (Liebhard et al. 2003). 'Discovery' showed a high level of resistance against a wide range of pathogen isolates under different environmental conditions (Laurens et al. 2003) and is a promising candidate for deciphering some of the genetic factors underlying scab resistance. Calenge et al. (2004) showed that 'Discovery' carries a combination of a major gene ( $\mathrm{Vg}$ on LG12) and specific or broad-spectrum QTL on LG2, LG5, LG13, LG15, and LG17.

In the present study, we explored the genetic basis of quantitative resistance against scab of another apple cultivar, 'Dülmener Rosenapfel', which is known to be resistant in unsprayed field conditions (A. Peil, personal communication 2007). During the European DARE (Durable Apple Resistance in Europe) project (Lespinasse et al. 2000), this cultivar showed resistance to a dozen inocula of $V$. inaequalis under different experimental conditions (Laurens et al. 2003), making it a prime candidate to study new and existing gene combinations for durable scab resistance.

\section{Material and methods}

\section{Plant material and Venturia inaequalis isolates}

A population of $275 \mathrm{~F}_{1}$ individuals (GaxDR) was derived from a cross between the susceptible cultivar 'Gala' (female parent) and the German resistant cultivar 'Dülmener Rosenapfel' (male parent). Twenty-five susceptible control individuals were derived from a cross between 'Golden Delicious' and 'Granny Smith'. In spring 2005, seedlings were grown in the greenhouse up to the 6-8 leaf stage before inoculation. After a first inoculation, the plants continued to grow for approximately 2 months before pruning and then were transferred for 2.5 months to a cold chamber $\left(1{ }^{\circ} \mathrm{C}\right)$ during the summer to mimic winter vernalization. After vernalization and when plant growth resumed, leaves were exposed to a second inoculation in autumn 2005. The parents could not be evaluated because they were not in the growth stage when their progeny and susceptible control individuals were inoculated, but they had been previously evaluated for their disease response in the same greenhouse by Laurens et al. (2003).

Six isolates of Venturia inaequalis were used for inoculation. Their origin and characteristics are described in Table 1. The monoconidial isolates 301 and 1066 are reference isolates from the INRA collection (Bénaouf and Parisi 2000). The monoconidial isolates EU-B04, EU-NL19, EU-D42, and EU-NL24 were from the European $V$. inaequalis collection of the European DARE project (Parisi et al. 2004).

\section{Pathological tests and phenotyping}

Two inoculation techniques were used, i.e., spray inoculation and droplet inoculation. In a first step, spray inoculation was used to identify qualitative and quantitative resistance factors in the GaxDR population. In a second step, droplet inoculation was used to characterize the interaction pattern of a new major gene previously identified by spray inoculation with $V$. inaequalis.

The GaxDR population (275 individuals) and susceptible control seedlings were spray-inoculated in spring 2005 (first screen). Spray inoculation was repeated on a subset of 155 GaxDR individuals and on susceptible control seedlings in autumn 2005 (second screen). For both screens, individuals were spray-inoculated in the greenhouse with a mixture of the same 5 isolates according to the conditions described by Chevalier et al. (1991). The 5 isolates (EU-B04, EU-NL19, EU-D42, EU-NL24, and 1066, Table 1) were prepared separately, as described by Parisi and Lespinasse (1996), and mixed in equal proportions. The final concentration of each isolate was about $8 \times 10^{4}$ conidia $/ \mathrm{mL}$. The rate of germinated conidia ranged from $56 \%$ to $93 \%$ after $24 \mathrm{~h}$ on an agar plate. After inoculation, the seedlings were incubated under transparent plastic sheets. Humidity was maintained at $90 \%$ by misting the greenhouse (with a fogging system) and the air temperature was maintained at $18{ }^{\circ} \mathrm{C}$ for $48 \mathrm{~h}$ to allow conidia germination. The seedlings were then taken out of the sheets, and the humidity was reduced to $70 \%$ and the temperature to $17{ }^{\circ} \mathrm{C}$ until scoring.

A subset of 120 GaxDR individuals was droplet-inoculated in autumn 2005. Six isolates were used for droplet inoculation, including the 5 isolates used for spray inoculation and another one (301, Table 1). Seedlings were inoculated 
Table 1. Characteristics of the Venturia inaequalis monoconidial isolates tested on 'Gala' $\times$ 'Dülmener Rosenapfel' progeny.

\begin{tabular}{lllll}
\hline Isolate & Host cultivar or hybrid $^{a}$ & Country & Race & Inoculation technique $^{c}$ \\
\hline 301 & 'Prima' $\times$ 'KI 40' & Germany & 1 & Droplet \\
EU-B04 & 'Golden Delicious' & Belgium & 1 & Spray and droplet \\
EU-NL19 & 'Golden Delicious' & The Netherlands & 1 & Spray and droplet \\
EU-D42 & 'Prima' & Germany & 6 & Spray and droplet \\
1066 & Malus floribunda 821 & France & 7 & Spray and droplet \\
EU-NL24 & 'Prima' & The Netherlands & $6+7^{b}$ & Spray and droplet \\
\hline
\end{tabular}

${ }^{a}$ Host cultivars or hybrids from which isolates were collected.

${ }^{b}$ Isolate combining the virulences of races 6 and 7 .

'Isolates were included in the mixture used for spray inoculation and (or) were tested separately for droplet inoculation.

with each isolate separately, the final conidia concentration was about $4 \times 10^{4}$ conidia/mL, and the rate of germinated conidia ranged from $53 \%$ to $92 \%$. The 120 individuals were distributed into three groups of 40. Each group was tested with two isolates (group 1: isolates 301 and 1066; group 2: isolates EU-NL19 and EU-NL24; group 3: isolates EU-B04 and EU-D42) and every plant of a group was simultaneously, but separately, inoculated with the two isolates. The droplet inoculation technique was described by Bus et al. (2005b). The seedlings were inoculated by placing $150 \mu \mathrm{L}$ of inoculum into small inoculation chambers, which were clipped onto the youngest expanded leaf of actively growing shoots. The seedlings were incubated under transparent plastic sheets for $48 \mathrm{~h}$, and the inoculation chambers were then removed. The environmental conditions in the greenhouse were the same as for the spray inoculation technique.

Chlorotic-type symptoms and sporulation intensity were scored on leaves. The presence or absence of chlorotic-type symptoms was scored at 7 days (spray) or at 11 and 19 days (droplet) after inoculation. For spray inoculation, the sporulation intensity was scored at 14, 21, and 28 days after inoculation following an ordinal scale corresponding to the percentage of leaf surface showing sporulation (described by Croxall et al. 1952 and modified by Parisi et al. 1993). The ordinal scale was as follows: 0, no sporulation; 1, $0<$ sporulation $\leq 1 \% ; 2,1 \%<$ sporulation $\leq 5 \% ; 3$, $5 \%<$ sporulation $\leq 10 \% ; 4,10 \%<$ sporulation $\leq 25 \% ; 5$, $25 \%<$ sporulation $\leq 50 \% ; 6,50 \%<$ sporulation $\leq 75 \%$; and $7,75 \%<$ sporulation $\leq 100 \%$. AUDPC (area under the disease progress curve) was computed and used to measure scab susceptibility using the ordinal data from the three dates.

\section{Statistical analyses}

The $\chi^{2}$ test was used to compare the chlorotic-type reaction segregation in the GaxDR progeny with 1:1 segregation. The Mann-Whitney-Wilcoxon test was used to compare AUDPC means of two samples, while Spearman's rank correlation coefficient was implemented to measure correlation between AUDPC computed for both screens.

\section{DNA extraction and specific PCR amplification}

DNA from the progeny and parental genotypes was isolated from leaves of seedlings and grafted plants, respectively, using the QIAGEN DNeasy 96 Plant Kit (QIAGEN, Hilden, Germany).
Eighty-three (83) simple sequence repeat (SSR) markers, previously described by Liebhard et al. (2002), Vinatzer et al. (2004), and Silfverberg-Dilworth et al. (2006), were used to screen the GaxDR progeny. An additional SSR marker, HB09-SSR (G.A.L. Broggini et al., unpublished data), was derived from a bacterial artificial chromosome (BAC) clone (Vinatzer et al. 2001) that was isolated using a probe derived from the HcrVf2 scab resistance gene (homologous to the Cladosporium fulvum resistance genes of the $V f$ region). The set of 84 SSR markers was selected on the basis of polymorphism between 'Dülmener Rosenapfel' and 'Gala', and the distribution spanning the apple genome as assessed in the reference genetic map of Silfverberg-Dilworth et al. (2006). The estimated SSR coverage was about $65 \%$ of the genome based on the 'Discovery' reference map (SilfverbergDilworth et al. 2006).

PCR amplification of SSR from genomic DNA was performed as described by Gianfranceschi et al. (1998) with minor modifications, including $0.33 \mu \mathrm{mol} / \mathrm{L}$ of both forward and reverse primers, and REDTaq DNA Polymerase (SigmaAldrich Corporation, St. Louis, Missouri, USA). Uniplex SSR amplification was done in a Peltier Thermal Cycler (MJ Research, Waltham, Massachusetts, USA) as described by Gianfranceschi et al. (1998) with minor modifications: 1 cycle of $2 \mathrm{~min} 30 \mathrm{~s}$ at $94{ }^{\circ} \mathrm{C}$; 5 cycles of $30 \mathrm{~s}$ at $94{ }^{\circ} \mathrm{C}$, $1 \mathrm{~min}$ annealing at $60{ }^{\circ} \mathrm{C}$ (dropping $1{ }^{\circ} \mathrm{C} /$ cycle), $1 \mathrm{~min}$ at $72{ }^{\circ} \mathrm{C}$; 30 cycles of $30 \mathrm{~s}$ at $94{ }^{\circ} \mathrm{C}, 1 \mathrm{~min}$ at $55^{\circ} \mathrm{C}, 1 \mathrm{~min}$ at $72{ }^{\circ} \mathrm{C}$; and a final extension cycle of $10 \mathrm{~min}$ at $72{ }^{\circ} \mathrm{C}$. A half volume of denaturing gel loading buffer $(80 \%$ deionized formamide, $10 \mathrm{mmol} / \mathrm{L}$ EDTA $\mathrm{pH} 8.0,1 \mathrm{mg} / \mathrm{mL}$ xylene cyanol, $1 \mathrm{mg} / \mathrm{mL}$ bromophenol blue) was added to the PCR product and heated at $95{ }^{\circ} \mathrm{C}$ for $5 \mathrm{~min}$. Products were separated on $7 \mathrm{~mol} / \mathrm{L}$ urea denaturing $5 \%$ polyacrylamide sequencing gels by electrophoresis at $60 \mathrm{~W}$ for $2 \mathrm{~h}$. PAGE gels were stained using silver nitrate as described by Creste et al. (2001).

Multiplex SSR amplification was performed with the QIAGEN Multiplex PCR Kit. The PCR amplification solution consisted of an $11 \mu \mathrm{L}$ reaction volume containing $5 \mathrm{ng}$ of apple genomic DNA, $1 \times$ QIAGEN Multiplex PCR Master Mix, and $0.2 \mu \mathrm{mol} / \mathrm{L}$ of each primer. SSR amplifications were done in a Peltier Thermal Cycler with the following programme: 1 cycle of $15 \mathrm{~min}$ at $94{ }^{\circ} \mathrm{C} ; 30$ cycles of $30 \mathrm{~s}$ at $94{ }^{\circ} \mathrm{C}, 1 \mathrm{~min} 30 \mathrm{~s}$ at $55^{\circ} \mathrm{C}, 1 \mathrm{~min}$ at $72{ }^{\circ} \mathrm{C}$; 1 cycle of $15 \mathrm{~min}$ at $55{ }^{\circ} \mathrm{C}$; and a final extension cycle of $15 \mathrm{~min}$ at $72{ }^{\circ} \mathrm{C}$. PCR products were loaded onto an ABI PRISM 3130 
sequencer (Applied Biosystems, Foster City, California) with an internal 50-400 bp size standard (GeneScan 400HD ROX, Applied Biosystems). Data were collected with ABI PRISM Data Collection software V3.0 and analysed with ABI PRISM GeneMapper software V3.7 (Applied Biosystems).

\section{Selective genotyping}

All progeny at the extremes of the first-screen AUDPC scores (beyond one standard deviation from the mean) and $34 \%$ of the remaining progeny (within one standard deviation from the mean) were genotyped at every marker to obtain a representative population of 166 individuals (Fig. 1). These 166 individuals accounted for $60 \%$ of the entire progeny.

To demonstrate the efficiency of a maximum-likelihood approach for correcting the overestimation of QTL contributions to phenotypic variation, the entire GaxDR progeny of 275 individuals was genotyped for markers closest to the likelihood peaks of the detected QTL (see below).

\section{Genetic map construction}

The integrated female + male linkage map of GaxDR was constructed using JoinMap software V3.0 (Van Ooijen and Voorrips 2001; PRI, Wageningen, the Netherlands). The initial map construction was done using a critical LOD (logarithm of odds ratio) score of 6 to associate loci and generate linkage groups. Markers linked to their neighbors with LOD $\leq 3$ were assigned to linkage groups according to their respective positions on the apple reference linkage map (Silfverberg-Dilworth et al. 2006). Linkage analysis to refine the marker order within linkage groups was carried out using the standard default settings in JoinMap for LOD and REC thresholds (1.0 and 0.4, respectively). The final locus order was determined by extensive manual analysis of data points generating double crossovers between flanking loci. Recombination frequencies were converted to map distances using Kosambi's mapping function (Kosambi 1944), and segregation distortions of parental alleles were examined by the $\chi^{2}$ test with a 95\% confidence level. Linkage groups were assigned according to the position of common markers and numbering described by Maliepaard et al. (1998).

\section{QTL detection}

Two sets of 166 and 135 jointly phenotyped and genotyped individuals were available for QTL analyses for the first and second screens, respectively. Twenty individuals among the 155 inoculated for the second screen were stunted and not scored, leaving only 135 individuals for QTL analysis.

QTL detection was performed using AUDPC data with MapQTL software V4.0 (Van Ooijen et al. 2002; PRI, Wageningen, the Netherlands). MapQTL software is able to deal with a full-sib family derived from heterozygous parents of a cross-pollinating species (e.g., apple). The integrated linkage map was used for detection of both additive and dominance effects.

The AUDPC data scored in the first screen (i.e., with a normal distribution for the entire progeny) were used for interval mapping. A LOD threshold at which a QTL was declared significant $(p=0.05)$ was determined using 1000
Fig. 1. AUDPC distributions for the entire (275 individuals) 'Gala' $\times$ 'Dülmener Rosenapfel' progeny and for the subset selected for genetic studies (166 individuals), scored at the first screen. The Gaussian curve was plotted with data on the 275 individuals.

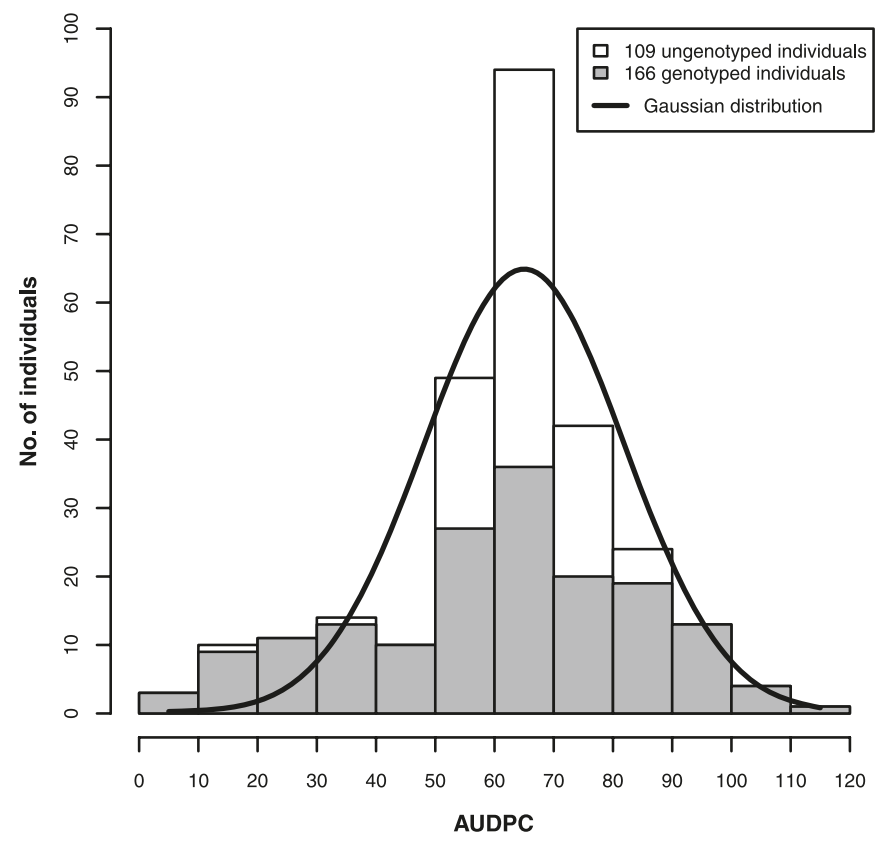

permutations (Churchill and Doerge 1994). Each significant QTL was characterized by its LOD score and its confidence interval, corresponding to a LOD score drop of 1 or 2 on either side of the likelihood peak with a probability over 90\% and 95\%, respectively (Van Ooijen 1992). A multiple analysis of variance (ANOVA), including molecular markers closest to the QTL peaks and their first-order interaction, was performed to test the effects of parental alleles and epistatic effects among QTL (SAS Institute Inc. 2000). QTL detection using AUDPC data in the second screen (non-normal distribution) was achieved by performing a Kruskal-Wallis test at each marker.

\section{QTL contributions to phenotypic variation}

Selective genotyping is known to lead to overestimation of QTL effects (Lander and Botstein 1989). Different solutions have been proposed to account for such overestimations (e.g., Muranty and Goffinet 1997; Xu and Vogl 2000), but they have been rarely implemented in QTL mapping software. MapQTL is able to take selective genotyping into account in single-interval mapping but not in multiple-QTL mapping (MQM function). Thus we developed the following approach to compute unbiased QTL contributions to phenotypic variation when there were several QTL. To validate our approach, we compared such unbiased QTL contributions with QTL contributions computed with complete genotyping data (i.e., with genotyping data from the entire GaxDR progeny of 275 individuals for markers closest to the QTL peaks).

1. QTL detection: QTL were detected using the single-QTL model of MapQTL (Interval Mapping function) using phenotypic and genotypic data from the 166 individuals.

2. Overestimated effects: ANOVA, using data from the 166 individuals and including markers closest to the 
QTL peaks, allowed joint analysis of the effects of QTL-associated markers and computation of the total percentage of explained phenotypic variation $\left(R^{2}\right)$. The contribution of each QTL-associated marker to phenotypic variation was calculated according to Scherrer (1984).

3. EM correction: an expectation-maximization (EM) computation implemented within NORM software (Schafer 1999) was used to estimate the corrected simple linear correlation coefficients between phenotype and QTL-associated markers or among QTL-associated markers. The EM-corrected simple linear correlation coefficients were then used for unbiased computation of the contribution of each QTL-associated marker and of the total $R^{2}$ according to Scherrer (1984).

4. Validation: complete genotyping of QTL-associated markers was analyzed on the entire unselected progeny and the total $R^{2}$ computed by ANOVA. The contribution of each QTL-associated marker was re-estimated (Scherrer 1984). These values (total $R^{2}$ and QTL contributions) were compared with the respective EM-corrected values computed in step 3 .

\section{Results}

\section{Phenotyping}

Susceptible control individuals displayed a high level of sporulation on leaves for both screens. AUDPC in the first screen $(83.7 \pm 15.3)$ was significantly lower $(p<0.02)$ than AUDPC in the second screen $(101.2 \pm 39.0)$. AUDPC in the GaxDR progeny exhibited different distributions between the first and second screens (Fig. 2). The distribution was close to normal in the first screen, whereas most individuals were either completely resistant or slightly susceptible, thus giving a highly skewed distribution, in the second screen. Average AUDPC was significantly higher $(p<0.0001)$ in the first screen $(59.0 \pm 27.1)$ than in the second screen $(22.0 \pm 34.1)$. The rank correlation coefficient between the two screens was $0.58(p<0.0001)$. Note that only individuals tested in both screens were included in the above analyses (susceptible controls and GaxDR progeny).

A total of 129 out of 275 individuals of the GaxDR progeny displayed a chlorotic-type reaction scored on leaves 7 days after inoculation with the mixture of 5 isolates of Venturia inaequalis (symptoms scored in the first screen and checked in the second screen on spray-inoculated seedlings; Table 2). This segregation did not differ significantly from $1: 1$ segregation $\left(P\left(\chi^{2} \geq 0.33\right)=0.57\right)$, which confirmed the assumed segregation of a single heterozygous gene in one of the parents.

\section{Genetic mapping of a new major gene in apple}

The chlorotic-type reaction was mapped as a qualitative trait at the distal end of LG6 in the apple genome. The gene associated with this reaction was found to derive from 'Dülmener Rosenapfel'. The gene was assigned Rvil4 (previously called Vdrl, Freslon et al. 2006) according to the new nomenclature of scab races proposed by Bus et al. (2008). On the integrated linkage map, the genetic distance between Rvil4 and the nearest marker, HB09-SSR, was $4.0 \mathrm{cM}$ ( $\mathrm{LOD}=52.0,253$ individuals). The size of the
Fig. 2. AUDPC for 'Gala' $\times$ 'Dülmener Rosenapfel' progeny after co-inoculation with five Venturia inaequalis isolates: (A) AUDPC distribution for the first screen; (B) AUDPC distribution for the second screen; (C) individuals plotted for both screens.

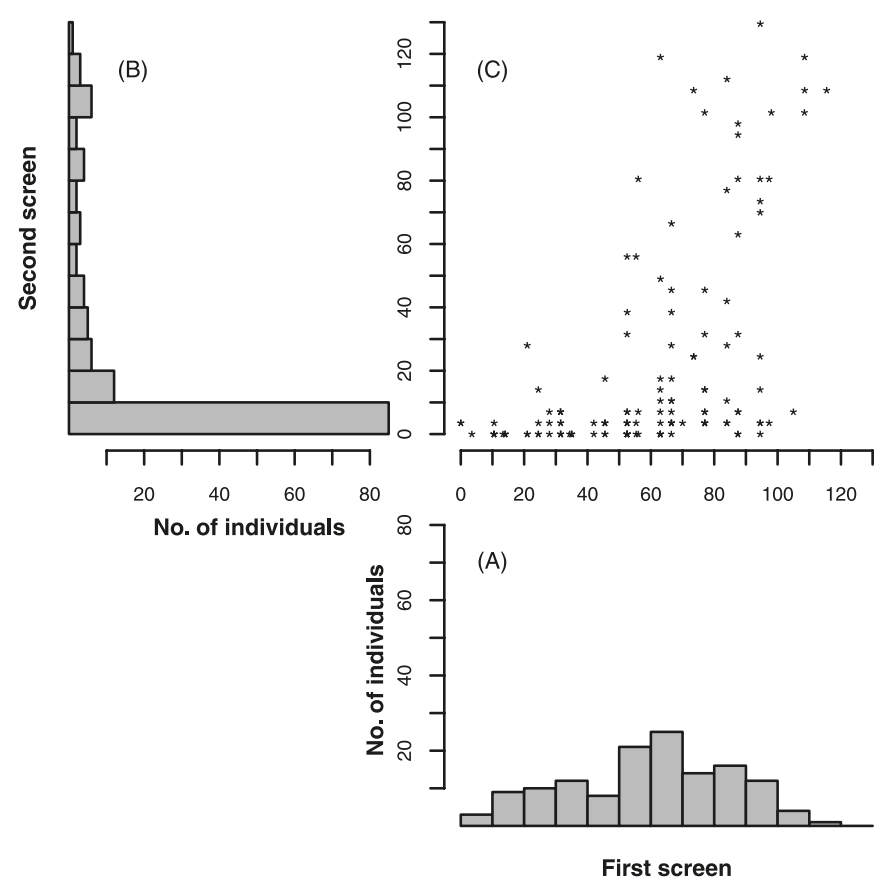

HB09-SSR allele coupling with Rvil4 was 210 bp. The linkage of Rvil4 to $\mathrm{CH} 03 \mathrm{~d} 07$ and NZ23g04 was also significant at an LOD of 21.65 and 5.22, respectively (Fig. 3).

\section{Characterization of the interaction pattern of $R v i 14$ with Venturia inaequalis}

Six independent monoconidial isolate inoculations were performed on three subsets of the segregating population. The chlorotic-type reaction was observed only with the two isolates EU-NL24 and EU-NL19 in individuals that had already shown this reaction in the first screen (apart from 1 to 3 escapes). Nevertheless, both isolates sporulated on leaves of some individuals carrying Rvi14, with EU-NL19 sporulating more frequently than EU-NL24 (47\% and 25\%, respectively). The other 4 isolates did not elicit the chlorotic-type reaction on individuals identified as carrying Rvil4 during the first screen. Isolates EU-D42 and EU-B04 caused sporulation on most of the individuals, whereas isolates 301 and 1066 sporulated on about one third of the individuals.

\section{QTL analyses}

For AUDPC data on 166 individuals in the first screen (selective genotyping), three QTL located on different linkage groups of the GaxDR integrated linkage map were significantly associated with scab resistance (Table 3). Two QTL were mapped to distal regions, i.e., one on LG6 $(\mathrm{LOD}=7.42$, Fig. 3 ) and one on LG11 (LOD $=13.69$, Fig. 3). The third QTL was mapped to the proximal region of LG17 (LOD = 11.32, Fig. 3). The QTL on LG6 was detected in 'Dülmener Rosenapfel' (male effect), while the QTL on LG11 was detected in 'Gala' (female effect) (Table 3). The QTL on LG17 was detected in both parents (Table 3). ANOVA including molecular markers closest to 
Table 2. Segregation of a chlorotic-type reaction in 'Gala' $\times$ 'Dülmener Rosenapfel' progeny after co-inoculation with five Venturia inaequalis isolates in both screens.

\begin{tabular}{lllllll}
\hline & \multicolumn{7}{l}{ Chlorotic-type reaction } \\
\cline { 3 - 7 } & No. of individuals & Present & Absent & d.t.s. ${ }^{*}$ & $\chi^{2}$ value & $p$ value \\
\hline 1st screen & 275 & 113 & 126 & 36 & 0.71 & 0.40 \\
2nd screen & 155 & 61 & 60 & 34 & 0.01 & 0.93 \\
1st screen + 2nd screen & 275 & 129 & 120 & 26 & 0.33 & 0.57 \\
\hline
\end{tabular}

*Difficult to score.

the QTL peaks and their first-order interaction showed slight epistatic interactions $(0.01<p<0.05)$ between LG11 (CH04h02) and LG6 (HB09-SSR) or LG17 (CH01h01). ANOVA was thus restricted to variation factors with a highly significant effect $(p<0.01)$, i.e., the male marker for the QTL on LG6, the female marker for the QTL on LG11, and both parents' markers for the QTL on LG17. The QTL on LG6 was located close to Rvil4 and the peak of the QTL co-localized with the marker HB09-SSR (Fig. 3). The quantitative resistance allele was involved in coupling with the favourable Rvil4 allele.

The three scab resistance QTL detected in the first screen were confirmed in the second screen in 135 individuals, i.e., QTL on LG6 (marker HB09-SSR, $p<0.001$ ), LG11 (marker CH04h02, $p<0.0001$ ), and LG17 (marker CH01h01, $p<$ 0.0001).

\section{QTL contributions to phenotypic variation}

$R^{2}$ were estimated from the first-screen phenotypic data. The total $R^{2}$ computed with the complete genotyping data for the 275 individuals was $42.7 \%$, whereas it was $54.8 \%$ for the selected data set for 166 individuals (Table 3). Selective genotyping resulted in overestimation of the total $R^{2}$ of about $12 \%$. On the other hand, the EM-corrected $R^{2}$ was $44.9 \%$, which is close to the $R^{2}$ computed with complete genotyping data. Similar patterns were observed for each QTL contribution to phenotypic variation (Table 3).

\section{Discussion}

\section{A new genomic region involved in apple scab resistance}

In addition to genomic regions already known to be involved in the control of scab resistance (major genes and QTL) in several apple cultivars, a new region was identified in the German cultivar 'Dülmener Rosenapfel' at the distal end of LG6. No other resistance genes, for scab or any other apple diseases, have been identified in this region of the apple genome. Despite some sporulation on seedlings exhibiting a chlorotic-type reaction, the Rvil4 gene appears to confer resistance to isolates EU-NL24 (virulences of races 6 and 7) and EU-NL19 (race 1), which would carry a corresponding avirulence gene. A similar situation has often been described for the $V f$ gene, which was found to confer complete resistance or only allow some sporulation in favourable controlled conditions, despite the fact that it has a substantial effect against Venturia inaequalis in the orchard when not overcome by races 6 and 7 (Chevalier et al. 1991; Gardiner et al. 1996; Gessler et al. 2006).

The Rvil4 gene determines a chlorotic-type reaction similar to the $V f$ gene phenotype (e.g., in 'Florina'). Moreover, the marker HB09-SSR was derived from a BAC clone that had been identified after hybridization with the HcrVf2 gene (Vinatzer et al. 2001), which is the most probable candidate for the $V f$ resistance gene (Xu and Korban 2002; Belfanti et al. 2004). Allo- or auto-polyploidy has been implicated in the origin of the apple genome (Darlington and Moffett 1930; Sax 1933; Challice 1981) and several duplicated regions have been identified in the apple genome (Chevreau et al. 1985; Chevreau and Laurens 1987; Maliepaard et al. 1998). The LG6 genomic region carrying the Rvil4 gene thus might be homeologous to the LG1 region carrying the $V f$ gene. These two chlorotic-type resistance genes (or gene clusters) might derive from the same ancestor and might have duplicated and diverged over evolutionary time.

Co-localization of resistance QTL with major resistance genes has been observed in apple (Durel et al. 2003; Bus et al. 2004) and in numerous other plant species such as rapeseed (Manzanares-Dauleux et al. 2000), common bean (Kelly and Vallejo 2004), and poplar (Jorge et al. 2005). Most of the resistance genes characterized at the molecular level belong to allelic series or to families of tightly linked genes (Hulbert et al. 2001). Therefore, major genes and colocalizing QTL could be members of the same allelic series, as suggested by Robertson (1985), or members of a multigene family. Co-localization of the QTL detected on LG6 with Rvil4 suggests that both resistance factors actually belong to the same locus, or that they are part of the same gene family. In the first case, the Rvil4 gene would control both the chlorotic-type reaction for isolates carrying a corresponding avirulence factor (EU-NL19 and EU-NL24) and some residual resistance to the virulent isolates (all of the other four). The mixed inoculum we used did not enable us to clarify whether Rvil4 had a general effect towards all the isolates tested or a differential effect dependent on the isolates present in the mixture and their relative proportions. Physical mapping and sequencing of BAC clones should reveal whether a single gene for Rvil4 or a cluster of genes at the Rvil4 locus provides differential resistance to apple scab.

\section{Two confirmed genomic regions involved in partial resistance to scab in apple}

Two QTL were detected on LG11 and LG17 of the GaxDR integrated linkage map with the mixture of isolates of Venturia inaequalis. These QTL have already been reported by Durel et al. (2003) in grafted progeny of 'Prima' $\times$ 'Fiesta' inoculated in a controlled climatic chamber with two monoconidial isolates of race 6. The QTL on LG17 was detected only in 'Fiesta', whereas the QTL on LG11 was detected in both 'Prima' and 'Fiesta'. QTL on LG11 and LG17 were also identified by Liebhard et al. (2003) in 'Fi- 
Fig. 3. Genomic localization of QTL for AUDPC and LOD plots for linkage groups 6, 11, and 17 of the 'Gala' $\times$ 'Dülmener Rosenapfel' integrated linkage map (interval mapping detection), after co-inoculation with five Venturia inaequalis isolates. Markers with a "_Ga" or a "_DR" extension are polymorphic only for 'Gala' or 'Dülmener Rosenapfel', respectively. Markers “_GaDR” are polymorphic for both parents. Distances are in centimorgans. QTL are represented by boxes, in which length represents the LOD - 1 confidence interval and extended lines represent that of LOD - 2. In the LOD plots, dotted lines represent the genome-wide LOD threshold.

esta' $\times$ 'Discovery' progeny grown in field conditions with a Swiss local inoculum. The QTL on LG11 was detected only in 'Discovery', whereas the QTL on LG17 was detected in both parents. Likewise, Calenge et al. (2004) showed a significant effect of the QTL on LG17 in seedlings and grafted plants derived from a 'Discovery' $\times$ 'TN10-8' cross, which were inoculated in greenhouse conditions with isolates of races 1, 6, 7, and ' $6+7$ ' and with two local inocula from France and Switzerland. This QTL was detected in 'Discovery'. The previous results and ours thus demonstrate the stability of these two genomic regions in the control of partial scab resistance. Indeed, these QTL are expressed in different genetic backgrounds, physiological stages, and environmental conditions. Based on previous studies, it could be postulated that these are broad-spectrum QTL, as supported by our study involving an inoculum consisting of various $V$. inaequalis isolates. Each isolate of our inoculum would need to be separately tested to confirm the broad spectrum of the QTL detected in 'Dülmener Rosenapfel' and 'Gala'.

\section{QTL contributions to phenotypic variation}

Selective genotyping resulted in overestimation of both the total $R^{2}$ and the QTL contributions to phenotypic variation. The correction by maximum likelihood (EM correction as proposed by $\mathrm{Xu}$ and $\mathrm{Vogl} 2000$ ) provided a reasonable $R^{2}$ estimation; the same was true for each QTL contribution. Here we validated this EM correction with experimental data, which has seldom been achieved to date. Another approach to correct the overestimation of QTL contributions was proposed by Lagarrigue et al. (2006) for QTL detected in chicken. It is based on the hypothesis of strict truncations of the normal distribution, i.e., a situation that was not adapted to our experimental conditions. In the present study, the slight overestimation observed in the EM correction when compared with complete genotyping might have been due to some deviation from the Gaussian distribution for AUDPC (Fig. 1).

The contributions of the three detected QTL ranged from $4.4 \%$ to $18.9 \%$ (Table 3 ). In a previous study (Durel et al. 2003), the QTL detected on LG11 explained 16\%-23\% of phenotypic variation, according to $V$. inaequalis isolates used in the greenhouse. The contribution of this QTL in field conditions was estimated at $11 \%$ (Liebhard et al. 2003). The contribution reported in our study (18.9\%) is in agreement with these previous results. On the other hand, the QTL detected on LG17 explained 10\%-13\% of phenotypic variation (Durel et al. 2003). In a second greenhouse
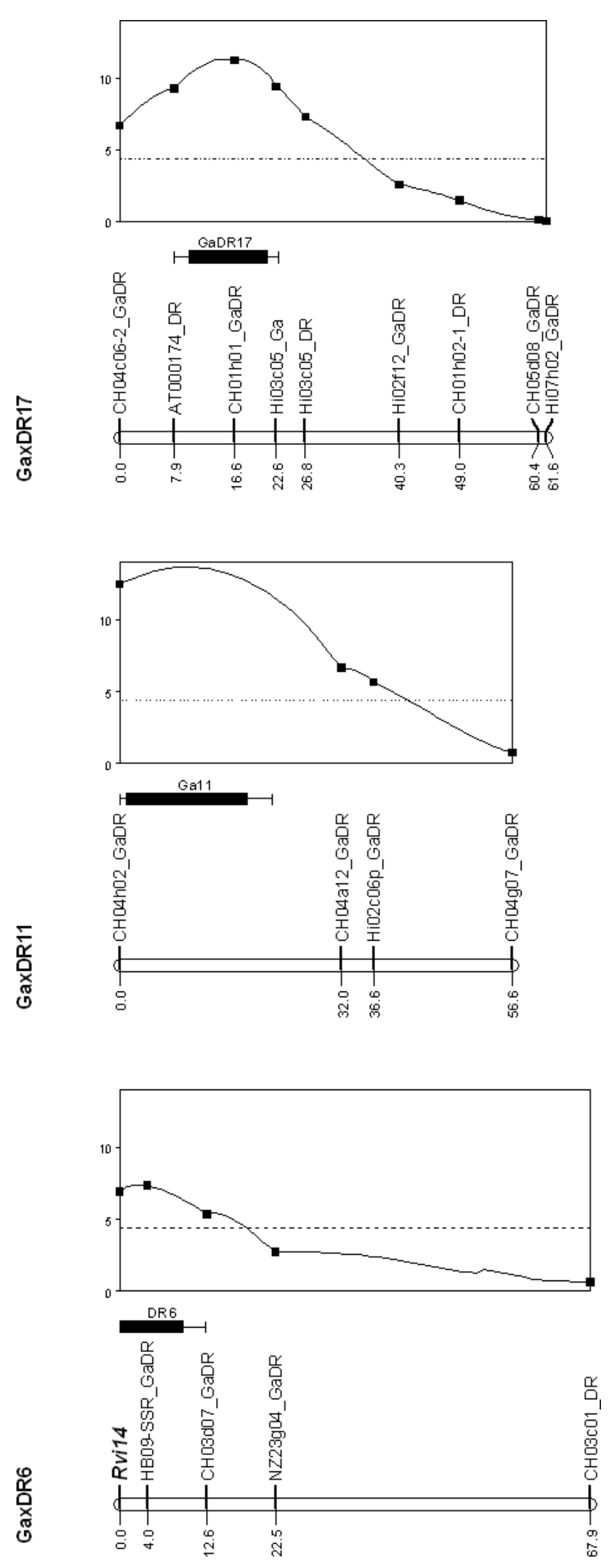

study (Calenge et al. 2004), the contribution of this QTL ranged from $5 \%$ to $19 \%$, but was higher than $10 \%$ with most tested isolates. The contribution of this QTL was about $23 \%$ in field conditions (Liebhard et al. 2003). In our study, 
Table 3. Individual and combined QTL contributions to scab disease variation in 'Gala' $\times$ 'Dülmener Rosenapfel' progeny after co-inoculation with five Venturia inaequalis isolates in the first screen.

\begin{tabular}{llllll}
\hline LG & Marker $^{a}$ & $\begin{array}{l}\text { Favourable allele } \\
\text { size }^{b}\end{array}$ & $\begin{array}{l}\text { Selective genotyping } \\
(166 \text { individuals })\end{array}$ & $\begin{array}{l}\text { EM correction } \\
(275 \text { individuals })\end{array}$ & $\begin{array}{l}\text { Complete genotyping } \\
(275 \text { individuals })\end{array}$ \\
\hline LG6 & HB09-SSR_DR & $210 \mathrm{bp}$ & 12.3 & 10.1 & 10.0 \\
LG11 & CH04h02_Ga & $185 \mathrm{bp}$ & 22.4 & 18.3 & 18.9 \\
LG17 & CH01h01_Ga & $136 \mathrm{bp}$ & 14.4 & 11.8 & 9.4 \\
& CH01h01_DR & $132 \mathrm{bp}$ & 5.7 & 4.7 & 4.4 \\
Total $R^{2}$ & & 54.8 & 44.9 & 42.7 \\
\hline Note: EM, expectation-maximization. & & \\
${ }^{a}$ SSR closest to the likelihood peak of each QTL. \\
${ }^{b}$ Favourable parental alleles associated with scab resistance. \\
${ }^{c}$ Overestimated values.
\end{tabular}

the QTL on LG17 accounted for a maximum contribution to phenotypic variation of $9.4 \%$, which is lower than noted in previous studies. Comparing QTL contributions is meaningful only if genetic variations are similar among different studies, since these contributions are assessed in relative terms (\%). However, data obtained in the above studies did not enable us to check this condition, so the above comparisons have to be considered cautiously.

\section{Genetic determinants of resistance}

The small number of genomic regions apparently involved in the quantitative scab resistance of 'Dülmener Rosenapfel' contrasts with the higher number of such regions detected for 'Discovery' scab resistance by Calenge et al. (2004). Different factors could explain this discrepancy: (i) phenotypes of each individual were less accurately estimated with single-copy seedlings, as in the present study, than with multiple-copy grafted plants, as tested in the 'Discovery' genetic analysis, and small QTL effects were thus less easily detected in our study; (ii) only one mixture of Venturia inaequalis isolates was used here, whereas 8 successive inocula with either monoconidial isolates or local isolates were used on the 'Discovery' progeny, so specific QTL may be missing here; (iii) some regions of the apple genome were not covered by markers in the present GaxDR linkage map, so a complete genome scan could not be performed; (iv) there may be more "homozygous" or epistatic undetected genetic factors in 'Dülmener Rosenapfel' than in 'Discovery'.

Note that AUDPC showed a normal distribution in the GaxDR progeny in the first screen, whereas it became highly skewed towards resistance in the second screen. This variation between the two screens has also been observed in other progenies derived from 'Dülmener Rosenapfel' (unpublished results). In the first screen, inoculated plants were very young seedlings (6-8 leaves after seed germination), whereas they were physiologically older in the second screen. The differences in data distribution between the first and the second screen may have been due to the differential expression of resistance at different physiological stages. The expression of seedling and adult plant resistances can be controlled by different genes, which is particularly common in several plant species (e.g., resistance to powdery mildew (Wang et al. 2005) or to stripe rust (Bariana et al. 2006) in wheat, resistance to leaf rust in barley (Qi et al. 1998), and resistance to stem canker in rapeseed (Delourme et al. 2004)). In other situations, some resistance genes are effective at both seedling and adult stages (Camargo et al. 1995), whereas others are effective only in adult plants (Zhang and Knott 1993). Such developmentally regulated resistance genes could also be present in apple.

Another interesting point was the presence of two QTL detected in 'Gala'. This cultivar is commonly regarded as a reference apple genotype for scab susceptibility. Indeed, so far 'Gala' has been considered susceptible, regardless of the $V$. inaequalis isolate. For instance, Laurens et al. (2003) tested the same isolates as those used in our experiment, except for isolate 301, and showed that 'Gala' was highly susceptible to all the tested isolates. Nevertheless, macroscopic and microscopic studies have shown that its level of susceptibility differs according to the fungal isolate (M. Chevalier, personal communication 2007). In the greenhouse, 'Gala' can thus be considered a "moderately" susceptible cultivar. Our study showed that 'Gala' carries at least two QTL whose effects alone are not sufficient to confer a high level of resistance. Many authors have pointed out the contribution of susceptible genotypes to disease resistance, and this effect was weak (Schön et al. 1993; Lefebvre and Palloix 1996) or moderate (Pilet et al. 1998; Paillard et al. 2004).

\section{Acknowledgments}

We thank C. Denancé, J.-M. Boré, M. Boucourt, L. Leclout, and Y. Rabineau for excellent technical assistance in the laboratory and greenhouse. L. Parisi and P. Expert are acknowledged for providing the Venturia inaequalis isolates. $\mathrm{V}$. Bus gave valuable advice on disease assessment for the droplet inoculation technique. We are grateful to N. Sapoukhina for her scientific assistance on expectation-maximization computation. We also thank S. Coëdel, Head of the Ouestgenopole genotyping platform (http://www.ouest-genopole. org/, INRA-UMR APBV-Bio3P, Le Rheu, France), for producing about half the genotypic data. This work was supported by a grant from the Communauté d'Agglomération Angers - Loire-Métropole to V. Soufflet-Freslon, and was partly supported by the Région Pays de la Loire within the framework of the Contrat Etat-Région 2000-2006, programme "Horticulture", and of the regional contract COSAVE 2007-2009.

\section{References}

Aldwinckle, H.S., Gustafson, H.L., and Lamb, R.C. 1976. Early determination of genotypes for apple scab resistance by forced 
flowering of test cross progenies. Euphytica, 25: 185-191. doi:10.1007/BF00041544.

Bariana, H.S., Parry, N., Barclay, I.R., Loughman, R., McLean, R.J., Shankar, M., et al. 2006. Identification and characterization of stripe rust resistance gene $\mathrm{Yr} 34$ in common wheat. Theor. Appl. Genet. 112: 1143-1148. doi:10.1007/s00122-006-0216-3. PMID:16435125.

Belfanti, E., Silfverberg-Dilworth, E., Tartarini, S., Patocchi, A., Barbieri, M., Zhu, J., et al. 2004. The HcrVf2 gene from a wild apple confers scab resistance to a transgenic cultivated variety. Proc. Natl. Acad. Sci. U.S.A. 101(3): 886-890. doi:10.1073/ pnas.0304808101. PMID:14715897.

Bénaouf, G., and Parisi, L. 1997. Pathogenicity of Venturia inaequalis strains from Malus floribunda 821: comparison with race 6 on apple clones. IOBC/WPRS Bull. 20(9): 8-11.

Bénaouf, G., and Parisi, L. 2000. Genetics of host-pathogen relationships between Venturia inaequalis races 6 and 7 and Malus species. Phytopathology, 90(3): 236-242. doi:10.1094/PHYTO. 2000.90.3.236.

Boudichevskaia, A., Flachowsky, H., Peil, A., Fischer, C., and Dunemann, F. 2006. Development of a multiallelic SCAR marker for the scab resistance gene $V r 1 / V h 4 / V x$ from R12740-7A apple and its utility for molecular breeding. Tree Genet. Genomes, 2(4): 186-195. doi:10.1007/s11295-006-0043-3.

Burdon, J.J. 1993. Genetic variation in pathogen populations and its implications for adaptation to host resistance. In Durability of disease resistance. Edited by T. Jacobs and J.E. Parlevliet. Kluwer Academic Publishers, Dordrecht, the Netherlands. pp. 41-56.

Bus, V., van de Weg, W.E., Durel, C.E., Gessler, C., Parisi, L., Rikkerink, E., et al. 2004. Delineation of a scab resistance gene cluster on linkage group 2 of apple. Acta Hortic. 663: 57-62.

Bus, V.G.M., Rikkerink, E.H.A., Weg, W.E.v.d., Rusholme, R.L., Gardiner, S.E., Bassett, H.C.M., et al. 2005a. The Vh2 and Vh4 scab resistance genes in two differential hosts derived from Russian apple R12740-7A map to the same linkage group of apple. Mol. Breed. 15(1): 103-116. doi:10.1007/s11032-004-3609-5.

Bus, V.G.M., Laurens, F., Weg, W.E.v.d., Rusholme, R.L., Rikkerink, E.H.A., Gardiner, S.E., et al. 2005b. The Vh8 locus of a new gene-for-gene interaction between Venturia inaequalis and the wild apple Malus sieversii is closely linked to the Vh2 locus in Malus pumila R12740-7A. New Phytol. 166(3): 1035-1049. doi:10.1111/j.1469-8137.2005.01395.x. PMID:15869661.

Bus, V.G.M., Rikkerink, E.H.A., Aldwinckle, H.S., Caffier, V., Durel, C.E., Gardiner, S., et al. 2008. A proposal for the nomenclature of Venturia inaequalis races. Acta Hortic. In press.

Calenge, F., Faure, A., Goerre, M., Gebhardt, C., Weg, W.E.v.d., Parisi, L., and Durel, C.E. 2004. Quantitative trait loci (QTL) analysis reveals both broad-spectrum and isolate-specific QTL for scab resistance in an apple progeny challenged with eight isolates of Venturia inaequalis. Phytopathology, 94(4): 370379. doi:10.1094/PHYTO.2004.94.4.370.

Camargo, L.E.A., Williams, P.H., and Osborn, T.C. 1995. Mapping of quantitative trait loci controlling resistance of Brassica oleracea to Xanthomonas campestris pv. campestris in the field and greenhouse. Phytopathology, 85(10): 1296-1300. doi:10.1094/ Phyto-85-1296.

Challice, J.S. 1981. Chemotaxonomic studies in the Rosaceae and the evolutionary origins of the subfamily Maloideae. Preslia, 53: 289-304.

Chevalier, M., Lespinasse, Y., and Renaudin, S. 1991. A microscopic study of the different classes of symptoms coded by the $V f$ gene in apple for resistance to scab (Venturia inaequalis).
Plant Pathol. 40(2): 249-256. doi:10.1111/j.1365-3059.1991. tb02374.x.

Chevreau, E., and Laurens, F. 1987. The pattern of inheritance in apple (Malus $\times$ domestica Borkh.): further results from leaf isozyme analysis. Theor. Appl. Genet. 75(1): 90-95. doi:10. 1007/BF00249147.

Chevreau, E., Lespinasse, Y., and Gallet, M. 1985. Inheritance of pollen enzymes and polyploid origin of apple (Malus $\times$ domestica Borkh.). Theor. Appl. Genet. 71(2): 268-277.

Churchill, G.A., and Doerge, R.W. 1994. Empirical threshold values for quantitative trait mapping. Genetics, 138(3): 963-971. PMID:7851788.

Creste, S., Tulmann Neto, A., and Figueira, A. 2001. Detection of single sequence repeat polymorphisms in denaturing polyacrylamide sequencing gels by silver staining. Plant Mol. Biol. Rep. 19(4): 299-306. doi:10.1007/BF02772828.

Croxall, H.E., Gwynne, D.C., and Jenkins, J.E.E. 1952. The rapid assessment of apple scab on leaves. Plant Pathol. 1: 39-41. doi:10.1111/j.1365-3059.1952.tb00022.x.

Darlington, C.D., and Moffett, A.A. 1930. Primary and secondary chromosome balance in Pyrus. J. Genet. 22: 129-151.

Dayton, D.F., and Williams, E.B. 1968. Independent genes in Malus for resistance to Venturia inaequalis. Proc. Am. Soc. Hortic. Sci. 92: 89-94.

Delourme, R., Pilet-Nayel, M.L., Archipiano, M., Horvais, R., Tanguy, X., Rouxel, T., et al. 2004. A cluster of major specific resistance genes to Leptosphaeria maculans in Brassica napus. Phytopathology, 94(6): 578-583. doi:10.1094/PHYTO.2004.94. 6.578 .

Durel, C.E., Parisi, L., Laurens, F., Weg, W.E.v.d., Liebhard, R., and Jourjon, M.F. 2003. Genetic dissection of partial resistance to race 6 of Venturia inaequalis in apple. Genome, 46(2): 224 234. doi:10.1139/g02-127. PMID:12723038.

Freslon, V., Bus, V.G.M., Gianfranceschi, L., Patocchi, A., and Durel, C.E. 2006. Identification and genetic characterisation of $V d r l$, a new major scab resistance gene from the apple cultivar 'Dülmener Rosenapfel'. In 3rd International Rosaceae Genomics Conference, Napier, New Zealand, March 2006. p. 63. Available from http://www.bioinfo.wsu.edu/gdr/community/conferences/ RG3_abstracts.pdf. [Abstr.]

Gardiner, S.E., Bassett, H.C.M., Noiton, D.A.M., Bus, V.G.M., Hofstee, M.E., White, A.G., et al. 1996. A detailed linkage map around an apple scab resistance gene demonstrates that two disease resistance classes both carry the $V f$ gene. Theor. Appl. Genet. 93: 485-493. doi:10.1007/BF00417939.

Gessler, C., Patocchi, A., Sansavini, S., Tartarini, S., and Gianfranceschi, L. 2006. Venturia inaequalis resistance in apple. Crit. Rev. Plant Sci. 25: 473-503. doi:10.1080/07352680601015975.

Gianfranceschi, L., Seglias, N., Tarchini, R., Komjanc, M., and Gessler, C. 1998. Simple sequence repeats for the genetic analysis of apple. Theor. Appl. Genet. 96(8): 1069-1076. doi:10. 1007/s001220050841.

Hemmat, M., Brown, S.K., and Weeden, N.F. 2002. Tagging and mapping scab resistance genes from R12740-7A apple. J. Am. Soc. Hortic. Sci. 127(3): 365-370.

Hulbert, S.H., Webb, C.A., Smith, S.M., and Sun, Q. 2001. Resistance gene complexes: evolution and utilization. Annu. Rev. Phytopathol. 39(1): 285-312. doi:10.1146/annurev.phyto.39.1. 285. PMID:11701867.

Jorge, V., Dowkiw, A., Faivre-Rampant, P., and Bastien, C. 2005. Genetic architecture of qualitative and quantitative Melampsora larici-populina leaf rust resistance in hybrid poplar: genetic mapping and QTL detection. New Phytol. 167(1): 113-127. doi:10.1111/j.1469-8137.2005.01424.x. PMID:15948835. 
Kelly, J.D., and Vallejo, V.A. 2004. A comprehensive review of the major genes conditioning resistance to anthracnose in common bean. HortScience, 39(6): 1196-1207.

Kosambi, D.D. 1944. The estimation of map distances from recombination values. Ann. Eugen. 12: 172-175.

Lagarrigue, S., Pitel, F., Carré, W., Abasht, B., Le Roy, P., Neau, A., et al. 2006. Mapping quantitative trait loci affecting fatness and breast muscle weight in meat-type chicken lines divergently selected on abdominal fatness. Genet. Sel. Evol. 38: 85-97. doi:10.1051/gse:2005028. PMID:16451793.

Lander, E.S., and Botstein, D. 1989. Mapping Mendelian factors underlying quantitative traits using RFLP linkage maps. Genetics, 121: 185-199. PMID:2563713.

Laurens, F. 1999. Review of the current apple breeding programmes in the world: objectives for scion cultivar improvement. Acta Hortic. 484: 163-170.

Laurens, F., Chevalier, M., Dolega, E., Genneri, F., Goerre, M., Fischer, C., et al. 2003. Local European cultivars as sources of durable scab resistance in apple. Acta Hortic. 663: 115-121.

Lebeda, A. 1992. The level of field resistance to Bremia lactucae in lettuce (Lactuca sativa) cultivars carrying the resistance gene Dm11. Plant Breed. 108(2): 126-131. doi:10.1111/j.1439-0523. 1992.tb00111.x.

Lefebvre, V., and Palloix, A. 1996. Both epistatic and additive effects of QTLs are involved in polygenic induced resistance to disease: a case study, the interaction pepper - Phytophtora capsici Leonian. Theor. Appl. Genet. 93: 503-511. doi:10.1007/ BF00417941.

Lespinasse, Y. 1989. Breeding pome fruits with stable resistance to disease: genes, resistance mechanisms, present work and prospects. IOBC/WPRS Bull. 12: 100-115.

Lespinasse, Y., Durel, C.E., Laurens, F., Parisi, L., Chevalier, M., and Pinet, C. 2000. A European project: D.A.R.E. — durable apple resistance in Europe (FAIR5 CT97-3898) durable resistance of apple to scab and powdery-mildew: one step more towards an environmental friendly orchard. Acta Hortic. 538(1): 197-200.

Liebhard, R., Gianfranceschi, L., Koller, B., Ryder, C.D., Tarchini, R., Weg, W.E.v.d., and Gessler, C. 2002. Development and characterisation of 140 new microsatellites in apple (Malus $\times$ domestica Borkh.). Mol. Breed. 10(4): 217-241. doi:10.1023/ A: 1020525906332.

Liebhard, R., Koller, B., Patocchi, A., Kellerhals, M., Pfammatter, W., Jermini, M., and Gessler, C. 2003. Mapping quantitative field resistance against apple scab in a 'Fiesta' $\times$ 'Discovery' progeny. Phytopathology, 93(4): 493-501. doi:10.1094/PHYTO. 2003.93.4.493.

Lindhout, P. 2002. The perspectives of polygenic resistance in breeding for durable disease resistance. Euphytica, 124(2): 217226. doi:10.1023/A:1015686601404.

MacHardy, W.E., Gadoury, D.M., and Gessler, C. 2001. Parasitic and biological fitness of Venturia inaequalis: relationship to disease management strategies. Plant Dis. 85(10): 1036-1051. doi:10.1094/PDIS.2001.85.10.1036.

Maliepaard, C., Alston, F.H., Arkel, G.v., Brown, L.M., Chevreau, E., Dunemann, F., et al. 1998. Aligning male and female linkage maps of apple (Malus pumila Mill.) using multi-allelic markers. Theor. Appl. Genet. 97(1/2): 60-73. doi:10.1007/ s001220050867.

Manzanares-Dauleux, M.J., Delourme, R., Baron, F., and Thomas, G. 2000. Mapping of one major gene and of QTLs involved in resistance to clubroot in Brassica napus. Theor. Appl. Genet. 101(5/6): 885-891. doi:10.1007/s001220051557.

Muranty, H., and Goffinet, B. 1997. Selective genotyping for location and estimation of the effect of a quantitative trait locus. Biometrics, 53: 629-643. doi:10.2307/2533963.

Paillard, S., Schnurbusch, T., Tiwari, R., Messmer, M., Winzeler, M., Keller, B., and Schachermayr, G. 2004. QTL analysis of resistance to fusarium head blight in Swiss winter wheat (Triticum aestivum L.). Theor. Appl. Genet. 109: 323-332. doi:10.1007/ s00122-004-1628-6. PMID:15014875.

Parisi, L., and Lespinasse, Y. 1996. Pathogenicity of Venturia inaequalis strains of race 6 on apple clones (Malus sp.). Plant Dis. 80(10): 1179-1183.

Parisi, L., Lespinasse, Y., Guillaumes, J., and Kruger, J. 1993. A new race of Venturia inaequalis virulent to apples with resistance due to the $V f$ gene. Phytopathology, 83(5): 533-537. doi:10.1094/Phyto-83-533.

Parisi, L., Fouillet, V., Schouten, H.J., Groenwold, R., Laurens, F., Didelot, F., et al. 2004. Variability of the pathogenicity of Venturia inaequalis in Europe. Acta Hortic. 663(1): 107-113.

Parlevliet, J.E. 1993. What is durable resistance, a general outline. In Durability of disease resistance. Edited by T. Jacobs and J.E. Parlevliet. Kluwer Academic Publishers, Dordrecht, the Netherlands. pp. 23-39.

Parlevliet, J.E. 2002. Durability of resistance against fungal, bacterial and viral pathogens; present situation. Euphytica, 124(2): 147-156. doi:10.1023/A:1015601731446.

Patocchi, A., Bigler, B., Koller, B., Kellerhals, M., and Gessler, C. 2004. Vr2: a new apple scab resistance gene. Theor. Appl. Genet. 109(5): 1087-1092. doi:10.1007/s00122-004-1723-8. PMID:15221140.

Pilet, M.L., Delourme, R., Foisset, N., and Renard, M. 1998. Identification of loci contributing to quantitative field resistance to blackleg disease, causal agent Leptosphaeria maculans (Desm.) Ces. et de Not., in winter rapeseed (Brassica napus L.). Theor. Appl. Genet. 96: 23-30. doi:10.1007/s001220050704.

Qi, X., Niks, R.E., Stam, P., and Lindhout, P. 1998. Identification of QTLs for partial resistance to leaf rust (Puccinia hordei) in barley. Theor. Appl. Genet. 96: 1205-1215. doi:10.1007/ s001220050858.

Robertson, D. 1985. A possible technique for isolating genic DNA for quantitative traits in plants. J. Theor. Biol. 117: 1-10. doi:10. 1016/S0022-5193(85)80161-2.

SAS Institute Inc. 2000. SAS user's guide: statistics. SAS Institute Inc., Cary, N.C.

Sax, K. 1933. The origin of the Pomoideae. Proc. Am. Soc. Hortic. Sci. 30: 147-150.

Schafer, J.L. 1999. NORM: Multiple imputation of incomplete multivariate data under a normal model. Version 2. Software for Windows 95/98/NT.

Scherrer, B. 1984. Corrélations et régressions multiples. In Biostatistique. Gaëtan Morin, Chicoutimi, Que. pp. 690-700.

Schön, C.C., Lee, M., Melchinger, A.M., Guthrie, W.D., and Woodman, W.L. 1993. Mapping and characterization of quantitative trait loci affecting resistance against second-generation European corn borer in maize with the aid of RFLPs. Heredity, 70: 648-659. doi:10.1038/hdy.1993.93.

Silfverberg-Dilworth, E., Matasci, C.L., Weg, W.E.v.d., Kaauwen, M.P.W.v., Walser, M., Kodde, L.P., et al. 2006. Microsatellite markers spanning the apple (Malus $\times$ domestica Borkh.) genome. Tree Genet. Genomes, 2(4): 202-224. doi:10.1007/s11295006-0045-1.

Tartarini, S., Gennari, F., Pratesi, D., Palazzetti, C., Sansavini, S., Parisi, L., et al. 2004. Characterisation and genetic mapping of a major scab resistance gene from the old Italian apple cultivar 'Durello Di Forli'. Acta Hortic. 663: 129-133.

Van Ooijen, J.W. 1992. Accuracy of mapping quantitative trait loci 
in autogamous species. Theor. Appl. Genet. 84(7-8): 803-811. doi:10.1007/BF00227388.

Van Ooijen, J.W., and Voorrips, R.E. 2001. JoinMap 3.0, Software for the calculation of genetic linkage maps. Plant Research International, Wageningen, the Netherlands.

Van Ooijen, J.W., Boer, M.P., Jansen, R.C., and Maliepaard, C. 2002. MapQTL 4.0, Software for the calculation of QTL positions on genetic maps. Plant Research International, Wageningen, the Netherlands.

Vinatzer, B.A., Patocchi, A., Gianfranceschi, L., Tartarini, S., Zhang, H., Gessler, C., and Sansavini, S. 2001. Apple contains receptor-like genes homologous to the Cladosporium fulvum resistance gene family of tomato with a cluster of genes cosegregating with $V f$ apple scab resistance. Mol. Plant Microbe Interact. 14(4): 508-515. doi:10.1094/MPMI.2001.14.4.508. PMID:11310738.

Vinatzer, B.A., Patocchi, A., Tartarini, S., Gianfranceschi, L., Sansavini, S., and Gessler, C. 2004. Isolation of two microsatellite markers from BAC clones of the $V f$ scab resistance region and molecular characterization of scab-resistant accessions in Malus germplasm. Plant Breed. 123(4): 321-326. doi:10.1111/j.14390523.2004.00973.x.

Wang, Z.L., Li, L.H., He, Z.H., Duan, X.Y., Zhou, Y.L., Chen, X.M., et al. 2005. Seedling and adult plant resistance to powdery mildew in Chinese bread wheat cultivars and lines. Plant Dis. 89: 457-463. doi:10.1094/PD-89-0457.

Williams, E.B., and Kuc, J. 1969. Resistance in Malus to Venturia inaequalis. Annu. Rev. Phytopathol. 7(1): 223-246. doi:10.1146/ annurev.py.07.090169.001255.

$\mathrm{Xu}$, M., and Korban, S.S. 2002. A cluster of four receptor-like genes resides in the $V f$ locus that confers resistance to apple scab disease. Genetics, 162(4): 1995-2006. PMID:12524365.

$\mathrm{Xu}, \mathrm{S}$., and Vogl, C. 2000. Maximum likelihood analysis of quantitative trait loci under selective genotyping. Heredity, 84: 525537. doi:10.1046/j.1365-2540.2000.00653.x. PMID:10849077.

Zhang, H., and Knott, D.R. 1993. Inheritance of adult plant resistance to leaf rust in six durum wheat cultivars. Crop Sci. 33: 694-697. 